\title{
The polyaromatic hydrocarbon $\beta$-naphthoflavone alters binding of YY1, Sp1, and Sp3 transcription factors to the Dp71 promoter in hepatic cells
}

\author{
CAROLINA BECERRIL-ESQUIVEL ${ }^{1,2^{*}}$, KATIA PEÑUELAS-URQUIDES ${ }^{1 *}$, ERIK BLANCAS-SÁNCHEZ ${ }^{1,2}$, \\ PABLO ZAPATA-BENAVIDES ${ }^{2}$, BEATRIZ SILVA-RAMÍREZ ${ }^{3}$, ARTURO CHÁVEZ-REYES ${ }^{4}$, \\ FABIOLA CASTORENA-TORRES ${ }^{5}$, BULMARO CISNEROS $^{6}$ and MARIO BERMÚDEZ DE LEÓN ${ }^{1,7}$
}

\begin{abstract}
${ }^{1}$ Departamento de Biología Molecular, Centro de Investigación Biomédica del Noreste, Instituto Mexicano del Seguro Social, Monterrey, Nuevo León 64720; ${ }^{2}$ Universidad Autónoma de Nuevo León, UANL, Facultad de Ciencias Biológicas, San Nicolás de los Garza, Nuevo León 66451; ${ }^{3}$ Departamento de Inmunogenética, Centro de Investigación Biomédica del Noreste, Instituto Mexicano del Seguro Social, Monterrey, Nuevo León 64720;

${ }^{4}$ Centro de Investigación y de Estudios Avanzados del IPN Unidad Monterrey, Apodaca, Nuevo León 66600;

${ }^{5}$ Escuela de Medicina, Tecnológico de Monterrey, Monterrey, Nuevo León 64710;

${ }^{6}$ Departamento de Genética y Biología Molecular, Centro de Investigación y de Estudios Avanzados del IPN unidad Zacatenco, Ciudad de México 07360; ${ }^{7}$ Departamento de Ciencias Básicas, Vicerrectoría de Ciencias de la Salud, Universidad de Monterrey, San Pedro Garza García, Nuevo León 66238, México
\end{abstract}

Received September 26, 2017; Accepted January 19, 2018

DOI: $10.3892 / \mathrm{mmr} .2018 .8626$

\begin{abstract}
The smallest product of the Duchenne muscular dystrophy gene, dystrophin (Dp)71, is ubiquitously expressed in nonmuscle tissues. We previously showed that Dp71 expression in hepatic cells is modulated in part by stimulating factor 1 (Sp1), stimulating protein 3 (Sp3), and yin yang 1 (YY1) transcription factors, and that the polyaromatic hydrocarbon, $\beta$-naphthoflavone ( $\beta$-NF), downregulates Dp71 expression. The aim of the present study was to determine whether $\beta$-NF represses Dp71 expression by altering mRNA stability or its promoter activity. Reverse transcription-quantitative polymerase chain reaction was used to measure half-life mRNA
\end{abstract}

Correspondence to: Dr Mario Bermúdez de León, Departamento de Biología Molecular, Centro de Investigación Biomédica del Noreste, Instituto Mexicano del Seguro Social, Avenue 2 de abril 501, Col. Independencia, Monterrey, Nuevo León 64720, México E-mail: mario.bermudez@imss.gob.mx

*Contributed equally

Abbreviations: AhR, aryl hydrocarbon receptor; $\beta$-NF, $\beta$-naphthoflavone; DMD, Duchenne muscular dystrophy; DMSO, dimethylsulfoxide; Dp71, dystrophin Dp71; EMSA, Electrophoretic Mobility Shift Assay; siRNA, small interfering RNA; Sp1, Stimulating factor 1; Sp3, stimulating protein 3; XRE, xenobiotic response element; YY1, Yin Yang 1

Key words: Dp71, mRNA, promoter, $\beta$-naphthoflavone, hepatic cells, transcription factors levels in $\beta$-NF-treated cells exposed to actinomycin $\mathrm{D}$, an inhibitor of transcription, for $0,4,8,12$ and $16 \mathrm{~h}$. Transient transfections with a plasmid carrying the Dp71 basal promoter fused to luciferase reporter gene were carried out in control and $\beta$-NF-treated cells. Electrophoretic mobility shift assays (EMSAs) were performed with labeled probes, corresponding to Dp71 promoter sequences, and nuclear extracts of control and $\beta$-NF-treated cells. To the best of our knowledge, the results demonstrated for the first time that this negative regulation takes place at the promoter level rather than the mRNA stability level. Interestingly, using EMSAs, $\beta$-NF reduced binding of YY1, Sp1, and Sp3 to the Dp71 promoter. It also suggests that $\beta$-NF may modulate the expression of other genes regulated by these transcription factors. In conclusion, $\beta$-NF represses Dp71 expression in hepatic cells by altering binding of YY1, Sp1, and Sp3 to the Dp71 promoter.

\section{Introduction}

Duchenne muscular dystrophy (DMD) is an X-linked recessive disorder characterized by severe and progressive muscle wasting and weakness due to degeneration of skeletal muscle. DMD primarily affects males with an estimated incidence of 1/3,500 male births (1). Females are usually asymptomatic but some female carriers manifest milder forms of the disease. This disorder is caused by defective expression of dystrophin, a $427-\mathrm{kDa}$ structural protein that is encoded by a $14-\mathrm{kb}$ mRNA transcribed from the DMD gene (2). Several studies of the DMD gene have led to the identification of dystrophin isoforms that exhibit tissue-specific expression and temporal regulation (3-6). These isoforms are named according their molecular weight as Dp260, Dp140, Dp116, and Dp71. The 
presence of at least seven independent promoters in the DMD gene accounts for the complexity of its transcriptional regulation.

Dp71, the smallest and the first expressed product of DMD gene during embryogenesis (7), is ubiquitously present in all tissues except in adult muscle cells (8). The N-terminal of Dp71 has seven unique residues but retains the cystein-rich and C-terminal domains of full-length dystrophin. Despite homologies between Dp71 and 427-kDa dystrophin, many studies have revealed different functions for both proteins (9-11). Dp71 shows high levels of expression in liver and brain (12). In neuronal cells, Dp71 has been involved in differentiation, cell cycle and adhesion processes (13-16). Other studies have associated the Dp71 expression to mental retardation, short stature in DMD patients and gastric adenocarcinoma prognosis (17-19).

Despite functional studies of Dp71, it has been necessary to identify the transcription factors and gene elements involved in its regulation in order to elucidate fully the pathways by which Dp71 expression is regulated in tissues. It has been established that the Dp71 promoter, which lacks a TATA box, can be transactivated by several transcription factors, including AP2 $\alpha$, YY1, and members of the Sp family. For example, in mouse myoblasts, the Dp71 promoter is consistently transactivated by Sp1 and Sp3, but during differentiation these factors disappear, resulting in downregulation of Dp71 (17). YY1, Sp1 and Sp3 also transactivate the Dp71 promoter in hepatic cells (18), while in neuronal cells the transactivation is mediated by Sp1 and AP2 $\alpha$ (19). Sp binding sites within the Dp71 promoter are highly conserved, which implies that the Sp proteins (particularly Sp1) can exert similar effects on Dp71 expression in different tissues and species.

The synthetic polyaromatic hydrocarbon, $\beta$-naphthoflavone $(\beta-N F)$, has been extensively used to analyze the effect of xenobiotics on a large number of genes involved in metabolic and adaptive processes $(20,21)$. In previous studies, we showed that both in vitro and in vivo expression of Dp71 in hepatic cells is repressed by $\beta-\mathrm{NF}$ (22). More recently, we identified different DNA elements on the Dp71 promoter that are crucial for Dp71 expression in hepatic cells, including binding sites for YY1 and the Sp family members. The functionality of these DNA elements and proteins was confirmed by EMSA, chromatin immunoprecipitation, and site-directed mutagenesis analysis (18). However, the underlying molecular mechanisms by which $\beta$-NF inhibits Dp71 expression remain poorly studied. The aim of the present study was to determine whether $\beta$-NF represses Dp71 expression at the level of messenger RNA stability or promoter activity.

\section{Materials and methods}

Cell cultures and treatments. Human HepG2 cells [American Type Culture Collection (ATTC) Manassas, VA, USA; HB-8065], derived from hepatoblastoma (23), were cultured in Minimum Essential Media (Invitrogen, Carlsbad, CA, USA) supplemented with $10 \%$ fetal bovine serum, $2 \mathrm{~m} \mathrm{ML-Glutamine,}$ $1.5 \mathrm{~g} / 1$ sodium bicarbonate, $1 \mathrm{mM}$ sodium pyruvate, $0.1 \mathrm{mM}$ non-essential aminoacids, penicillin (100 U/ml) and streptomycin $(100 \mu \mathrm{g} / \mathrm{ml})$. Mouse Hepa-1 cells (ATCC; CRL-1830), derived from hepatome, were cultured in Dulbecco's modified
Eagle's medium (Invitrogen) supplemented with $10 \%$ fetal bovine serum, $2 \mathrm{mM}$ L-Glutamine, $4.5 \mathrm{~g} / 1 \mathrm{D}$-Glucose, penicillin $(100 \mathrm{U} / \mathrm{ml})$ and streptomycin $(100 \mu \mathrm{g} / \mathrm{ml})$. Both cell lines were incubated at $37^{\circ} \mathrm{C}$ in a humidified atmosphere with $95 \%$ air and $5 \% \mathrm{CO}_{2}$. Cells were seeded on 6-well culture plates $\left(1.5 \times 10^{5}\right.$ cells per well) and treated for $24 \mathrm{~h}$ with $50 \mu \mathrm{M}$ of $\beta$-naphthoflavone (cat. no., N3633; Sigma, St. Louis, MO, USA) diluted in dimethyl sulfoxide (DMSO) or with DMSO alone as control (22). For all cell treatments, the final DMSO concentration was adjusted to $0.1 \%$. To inhibit transcription, both $\beta$-NF-treated or DMSO-treated cells were exposed to actinomycin D $(50 \mu \mathrm{g} / \mathrm{ml})$ for $0,4,8,12$ and $16 \mathrm{~h}$.

Total RNA extraction and reverse transcription-quantitative polymerase chain reaction. Total RNA was extracted from $\beta$-NF- or DMSO-treated Hepa-1 cells using the TRIzol reagent (Invitrogen) according to the manufacturer's instructions. RNA concentration and purity were estimated by optical density at 260 and $280 \mathrm{~nm}$ wavelength, and its integrity was corroborated by electrophoresis on $1 \%$ agarose gels stained with ethidium bromide. RNA was reversed transcribed with the M-MLV reverse transcriptase (Invitrogen) and subjected to real-time qPCR for Dp71, r18S and cytochrome P450 1A1 gene expression analysis, as previously described (22). RT-qPCR was performed following the MIQE guidelines (22) with the next conditions: Each $25-\mu 1$ reaction mixture consisted of $12.5 \mu \mathrm{l}$ of 2X TaqMan Master Mix (Applied Biosystems, Carlsbad, CA, USA), $1.25 \mu 1$ of forward/reverse primers (25 $\mu \mathrm{M}$ each primer) and hydrolysis probe $(10 \mu \mathrm{M})$, and $3 \mu \mathrm{l}$ of cDNA. Amplification was performed under the following conditions: pre-denaturation at $50^{\circ} \mathrm{C}$ for $2 \mathrm{~min}$ and $95^{\circ} \mathrm{C}$ for $10 \mathrm{~min}$; denaturation at $95^{\circ} \mathrm{C}$ for $15 \mathrm{sec}$; annealing and extension at $60^{\circ} \mathrm{C}$ for $1 \mathrm{~min}$. $\mathrm{mRNA}$ levels were normalized to the expression of the 18S rRNA housekeeping gene (cat. 4310893E; Applied Biosystems). Samples were processed and detected in a real-time PCR 7500 Fast System (Applied Biosystems). Assays were performed in technical replicates and negative controls where included in the same plate. Quantitative analyses of gene expression were conducted using the $2^{-\Delta \Delta \mathrm{Cq}}$ formula (24), where the first $\Delta \mathrm{Cq}$ is the difference between $\mathrm{Cq}$ values for Dp71 gene and r18S gene, and the $\Delta \Delta \mathrm{Cq}$ is the difference between $\Delta \mathrm{Cq}$ values of the $\beta$-naphtopflavone-treated and control samples. Finally, 2 to the power of negative $\Delta \Delta \mathrm{Ct}$ gets the fold gene expression.

Transient cell transfections and luciferase assays. The Dp71 promoter fragment (from -224 to +65 ) fused to luciferase gene (18) was transfected in human HepG2 and mouse Hepa-1 cells with Lipofectamine 2000 reagent (Invitrogen), according to manufacturer's instructions. Briefly, $3.6 \mu \mathrm{g}$ of p224-Luc and $400 \mathrm{ng}$ of phRL-CMV plasmids (the latter used as a control for normalizing transfection efficiency) were incubated with $250 \mu \mathrm{l}$ of DMEM without serum for $5 \mathrm{~min}$. In a separate microtube, the plasmids were mixed with $10 \mu \mathrm{l}$ Lipofectamine 2000 previously diluted in $250 \mu \mathrm{l}$ of DMEM without serum. After 20 min of incubation at room temperature, DNA-Lipofectamine complexes were added to $1 \times 10^{5}$ human or mouse cells. In each assay, pGL3 Basic Vector and pGL3 Control Vector (Promega, Madison, WI, USA) were transfected in parallel as negative and positive controls, respectively. After $5 \mathrm{~h}$, medium was 
replaced with DMEM supplemented with $10 \%$ fetal bovine serum.

Twenty-four hours after transfection the cells were exposed to $1,5,10$ or $50 \mu \mathrm{M} \beta$-NF or $0.1 \%$ DMSO (control) for $24 \mathrm{~h}$. Before luciferase activity determination cells were washed with $1 \mathrm{X}$ phosphate-buffered saline (PBS) solution, and then homogenized with 1X Passive Lysis Buffer (Promega) for $15 \mathrm{~min}$ on an oscillatory shaker. Firefly and Renilla luciferase activity was measured with the Dual-Luciferase Assay System (Promega) and the Modulus Luminometer (Turner BioSystems, Sunnyvale, CA, USA). Luciferase activity of DMSO-treated cells was set as $100 \%$. Blanks were analyzed by conducting luciferase activity assays in untransfected cells. Luciferase activity levels were normalized to the Renilla luciferase activity levels of the phRL-CMV vector from the same cell culture.

Preparation of nuclear extracts and electrophoretic mobility shift assays (EMSAs). Nuclear extracts were prepared according to Schreiber et al (1989) (25). Briefly, Hepa-1 cells were either untreated or exposed to $50 \mu \mathrm{M} \beta$-NF or $0.1 \%$ DMSO (vehicle control) for $24 \mathrm{~h}$. The cells were then washed with cold 1X PBS, resuspended in $400 \mu 1$ of cold buffer A [10 mM HEPES, (pH 7.9), $10 \mathrm{mM} \mathrm{KCl,} 0.1 \mathrm{mM}$ EDTA, $0.1 \mathrm{mM}$ EGTA, $1 \mathrm{mM}$ DTT and $0.5 \mathrm{mM}$ PMSF], and incubated for $15 \mathrm{~min}$ on ice. Afterwards, $25 \mu 1$ of $10 \%$ Igepal CA-630 solution (Sigma-Aldrich, St. Louis, MO, USA) was added to each sample, and cell disruption was performed by aspirating the contents several times through a 22 -gauge needle. The samples were centrifuged at $2,000 \mathrm{x}$ g for $5 \mathrm{~min}$ at $4^{\circ} \mathrm{C}$. Supernatants were removed and the nuclear pellets resuspended in $50 \mu \mathrm{l}$ of buffer $\mathrm{C}$ [20 mM HEPES (pH 7.9), $0.4 \mathrm{M}$ $\mathrm{NaCl}, 1 \mathrm{mM}$ EDTA, 1 mM EGTA, 1 mM DTT, 1 mM PMSF) with vigorous vortexing for $30 \mathrm{~min}$ at $4^{\circ} \mathrm{C}$. Samples were then centrifuged and the nuclear extracts isolated.

Nuclear extracts from untreated, DMSO-treated and $\beta$-NF-treated hepatic cells were subjected electrophoretic mobility-shift assays (EMSAs) using double-stranded oligonucleotide probes (YY1 and Sp1/Sp3) (18). These probes were end-labelled with $\left[\gamma^{3}{ }^{32 \mathrm{P}}\right]$-ATP (Amersham Pharmacia, GE Healthcare, Buckinghamshire, UK) using $10 \mathrm{U}$ of T4 polynucleotide kinase (Invitrogen), according to the manufacturer's instructions. EMSAs were carried out by two independent experiments on ice for $20 \mathrm{~min}$ in a $20-\mu l$ reaction mixture containing $10 \mathrm{mM}$ Tris- $\mathrm{HCl}$ (pH 8.0), $1 \mathrm{mM} \mathrm{MgCl}_{2}, 5 \mathrm{mM}$ $\mathrm{NaCl}, 0.5 \mathrm{mM}$ EDTA (pH 8.0), $0.5 \mathrm{mM}$ DTT, $4 \%$ glycerol, $15 \mu \mathrm{g}$ nuclear extract, $20 \mathrm{mM}$ spermidine, $50 \mathrm{ng} / \mu 1$ poly(dI:dC), and $0.2 \mathrm{pmol}$ of probe. Samples were separated on native polyacrylamide gels (6\%) and visualized by autoradiography.

Statistics. Data are expressed as the mean \pm standard deviation (SD). Statistical analyses were performed using the Mann Whitney U test with STATA version 8.0 program (Stata Corporation, College Station, TX, USA), and significant differences were considered at $\mathrm{P}<0.05$.

\section{Results}

To ascertain whether $\beta$-NF affects mRNA stability, Dp71 mRNA levels in Hepa-1 cells were measured by real-time
A

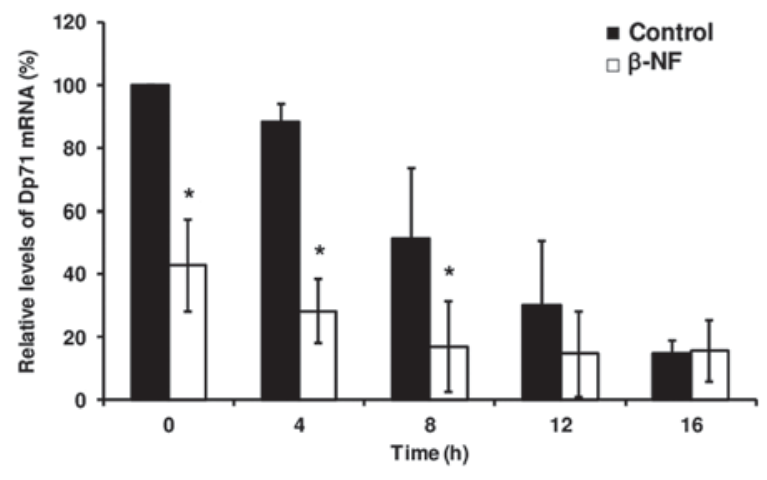

B

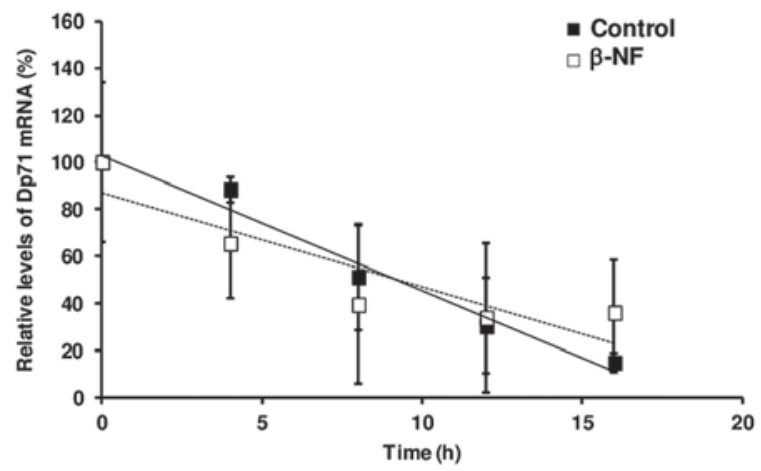

Figure 1. Effect of $\beta$-NF on Dp71 mRNA half-life in Hepa-1 cells. DMSOand $\beta$-NF-treated Hepa-1 cells were exposed to actinomycin D $(5 \mu \mathrm{g} / \mathrm{ml})$ at different times ( 0 to $16 \mathrm{~h}$ ) to inhibit the transcription. For each treatment, total RNA was extracted and reverse transcription coupled to real-time PCR was performed. Relative Dp71 mRNA expression levels were determined by the $2^{-\Delta \Delta C T}$ method (28). (A) Decay of Dp71 mRNA in hepatic cells, where the mRNA content of control cells (closed bars) at $0 \mathrm{~h}$ was set as $100 \%$; $\beta$-NF-treated cells (open bars). (B) Linear regression analysis of Dp71 mRNA decay in DMSO (closed squares) and $\beta$-NF-treated cells (open squares). Half-life was calculated at time when Dp71 mRNA content was at $50 \%$. Data are expressed as the mean $\pm \mathrm{SD}$. (error bars) of replicates from two independent experiments. " $\mathrm{P}<0.05$.

RT-qPCR. Our analysis confirms the transcriptional repression exerted by $\beta$-NF in a $60 \%$ decrease in the mean Dp71 mRNA level $(\mathrm{P}<0.05)$ that we previously observed, and it demonstrates that this repression occurs in a time-dependent manner and was maintained during transcription inhibition and subsequent mRNA decay in response to actinomycin D treatment (Fig. 1A). However, $\beta$-NF did not alter the mean half-life of Dp71 mRNA in hepatic cells compared to that in untreated cells The Dp71 mRNA half-life in both DMSO-treated $(9.11 \pm 2.9 \mathrm{~h})$ and $\beta-\mathrm{NF}$-treated hepatic cells $(9.36 \pm 1.6 \mathrm{~h})$ determined by our linear regression was not different (Fig. 1B). As expected, CYP1A1 expression in $\beta$-NF-treated cells was increased compared to that in DMSO-treated cells (data not shown).

To determine whether the $\beta$-NF-induced downregulation of Dp71 transcription occurs at the promoter level, mouse and human hepatic cells were transfected with a vector carrying the Dp71 proximal promoter prior to $\beta-\mathrm{NF}$ treatment. Dp71 promoter full repression in both cell lines upon $\beta$-NF treatment demonstrated that this xenobiotic interferes with Dp71 promoter activity (Fig. 2A), and $\beta$-NF downregulates Dp71 expression in a dose-dependent manner via suppressing Dp71 promoter activity rather than reducing Dp71 mRNA stability 

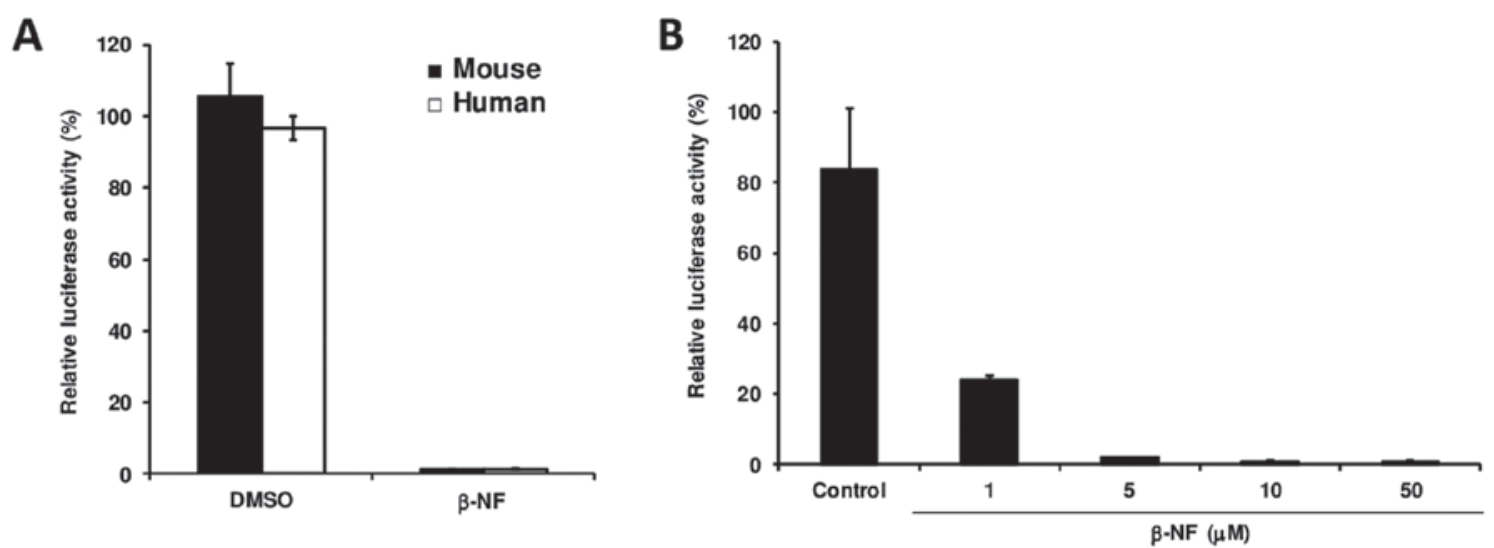

Figure 2. $\beta$-naphthoflavone represses Dp71 promoter activity in human and mouse hepatic cells. (A) Vector containing Dp71 promoter sequence (p244-Luc) fused to firefly luciferase reporter gene was co-transfected into Hepa-1 (closed bars) and HepG2 (open bars) cell lines together with control plasmid expressing Renilla reniformis luciferase, as described in Materials and methods. Cells were treated for $24 \mathrm{~h}$ with $50 \mu \mathrm{M} \beta$-naphthoflavone ( $\beta$-NF) or with dimethylsulfoxide (DMSO) as control. (B) Dose-dependent repression of Dp71 promoter activity by $\beta$-NF (1 to $50 \mu \mathrm{M}$ ) in Hepa-1 cells. Data shown are representative of three independent experiments. Luciferase activity of DMSO-treated cells was set as 100\%. Error bars indicate standard deviations.
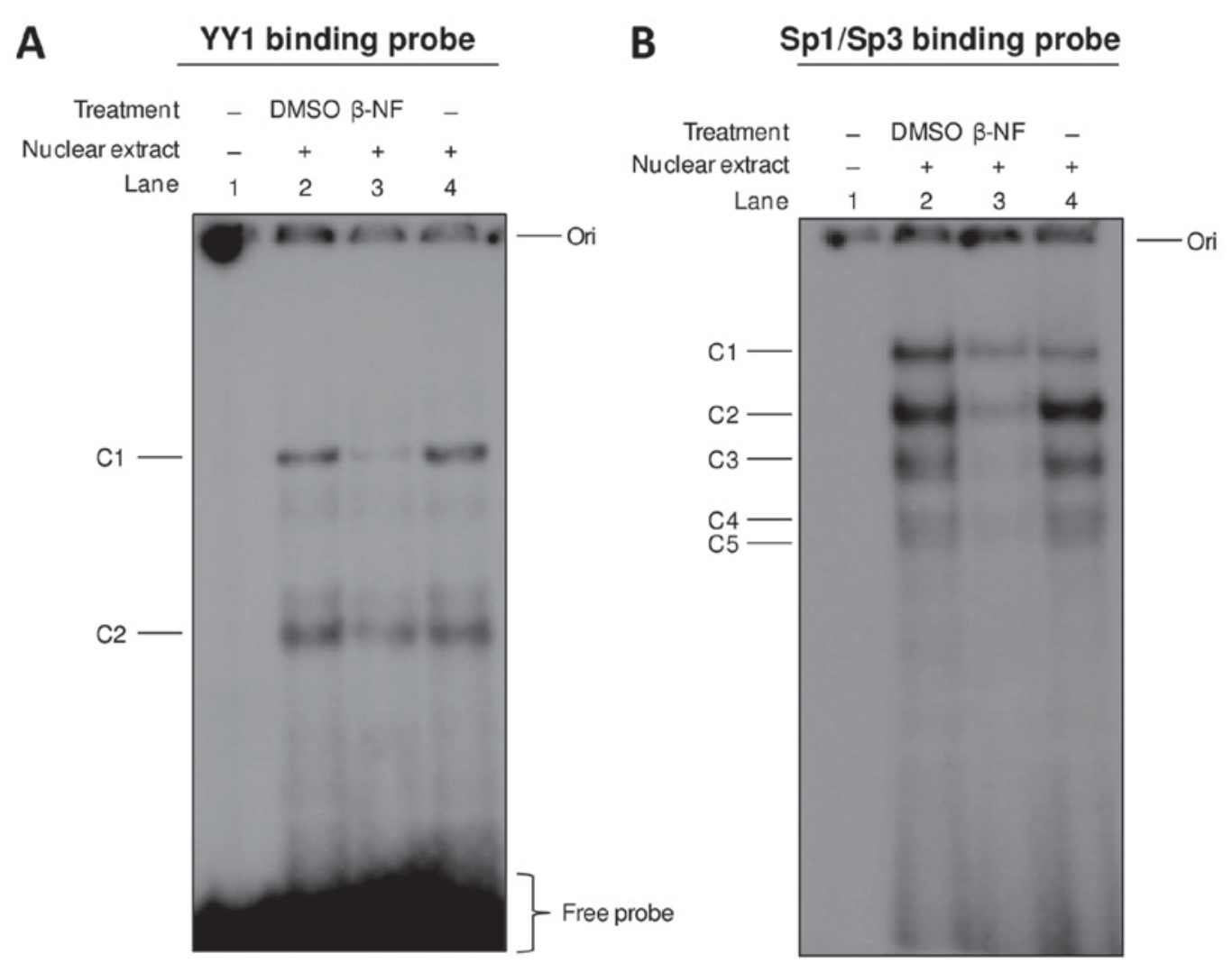

Figure 3. Effect of $\beta$-naphthoflavone on Sp1/Sp3 and YY1 binding to the Dp71 proximal promoter. EMSAs were performed by incubating nuclear extracts from Hepa-1 cells treated for $24 \mathrm{~h}$ with $50 \mu \mathrm{M} \beta$-Naphthoflavone ( $\beta$-NF) and dimethylsulfoxide (DMSO) as control. (A) Probe containing YY1-binding site. (B) Probe containing Sp1/Sp3 binding site. Major DNA-protein complexes are indicated as C1 to C5. Hepa-1 cells with no treatment were used as control. Gel image is representative of two independent results.

(Fig. 2B). Hepa-1 cells transfected with pGL3 control vector (harboring CMV promoter) and exposed to $\beta$-NF did not exhibit significant suppression (data not shown).

We previously demonstrated, by supershift assays, the binding of YY1, Sp1, and Sp3 to Dp71 proximal promoter (18); then we examined whether $\beta$-NF alters the interaction of these transcription factors. Nuclear extracts from DMSO-treated and $\beta$-NF-treated hepatic cells were subjected to EMSA using
YY1 and Sp1/Sp3 binding probes. As shown in Fig. 3, $\beta$-NF reduced binding of $\mathrm{YY} 1$ and $\mathrm{Sp} 1 / \mathrm{Sp} 3$ to their respective DNA elements (lanes 3, Fig. 3A and B, respectively), which has the clear implication that $\beta$-NF or its metabolites downregulate Dp71 expression in hepatic cell by inhibiting binding of these transcription factors to the Dp71 proximal promoter. By other hand, the probe bearing the XRE element (22) did not form any specific complex (data not shown). 


\section{Discussion}

Dp71 is widely expressed in non-muscle tissues and displays diverse functions in different tissues and cell types (15), however the molecular mechanisms underlying its expression remain poorly studied. Previously, we demonstrated that Dp71 expression is negatively regulated by the polyaromatic hydrocarbon $\beta-\mathrm{NF}$ as in vitro as in vivo in hepatic cells (22). Moreover, we demonstrated different DNA elements on Dp71 promoter that are crucial for Dp71 expression in hepatic cells, including binding sites for YY1 and the Sp family. The functionality of these DNA elements were confirmed by EMSA, chromatin immunoprecipitation and site-directed mutagenesis analysis (18). In the present study, we explored the mechanisms underlying the repressive effect of $\beta$-NF on Dp71 expression.

To ascertain whether $\beta$-NF affects mRNA stability, Dp71 mRNA levels in Hepa-1 cells were measured by quantitative real-time RT-qPCR. Our analysis confirms the transcriptional repression exerted by $\beta$-NF that we previously observed (22) and demonstrates that this repression occurs in a time-dependent manner. Despite this reduction in Dp71 expression, $\beta$-NF did not change the stability of the mRNA transcript. The Dp71 mRNA half-life in both DMSO-treated and $\beta$-NF-treated hepatic cells determined by our linear regression analysis $(9 \mathrm{~h})$ is markedly lower than that measured in myogenic cells $(20 \mathrm{~h})$ by Tennyson et al (26). This difference could be due to differential transcriptional mechanisms operating in each cell type.

We also determined whether the $\beta$-NF-induced downregulation of Dp71 transcription occurs at the promoter level by transfecting mouse and human hepatic cells with a vector carrying the Dp71 proximal promoter prior to $\beta$-NF treatment. Our data indicate that $\beta-\mathrm{NF}$ downregulates Dp71 expression in a dose-dependent manner via suppressing Dp71 promoter activity rather than reducing Dp71 mRNA stability. Furthermore, we observed this $\beta$-NF-induced reduction of Dp71 promoter activity in both HepG2 and Hepa-1 cell lines, indicating that this mechanism is conserved between human and mouse hepatic cells.

In functional studies, we have previously shown that mutations of YY1- and Sp-binding sites in Dp71 promoter significantly reduced its activity, and because the binding of $\mathrm{YY} 1, \mathrm{Sp} 1$, and $\mathrm{Sp} 3$ is relevant to Dp71 proximal promoter activity (18), we examined whether $\beta$-NF alters this interaction. $\beta$-NF remarkably decreased the binding of YY1, Sp1, and Sp3 to the Dp71 proximal promoter, which implies that $\beta-\mathrm{NF}$ and/or its metabolites may inhibit the expression of these transcription factors. Alternatively, this xenobiotic may alter post-translational modifications of these transcription factors, such as glycosylation, phosphorylation, ubiquitination, or acetylation, thereby reducing the affinity of these nuclear proteins for their respective DNA elements $(27,28)$. Further studies are required to determine how $\beta$-NF modifies YY1, $\mathrm{Sp} 1$, and Sp3 binding to the $\mathrm{Dp} 71$ promoter region.

Dp71 promoter sequence contains a single xenobiotic response element (XRE) at the position -63/-59 (22). This kind of element is recognized by the AhR/ARNT complex to regulate positively numerous genes involved in cellular metabolism, detoxification process or inflammatory process $(29,30)$. Nevertheless, we failed to observe interaction between of XRE and nuclear proteins from $\beta$-NF-treated hepatic cells, which indicate that the repressive effect of $\beta$-NF on Dp71 promoter activity is independent of the Aryl hydrocarbon receptor.

In conclusion, our study demonstrates that $\beta$-NF-induced repression of Dp71 expression in hepatic cells take place at the promoter level, via inhibition of YY1, Sp1, and Sp3 binding to the Dp71 promoter. Further studies are warranted to determine whether $\beta$-NF can alter the expression of other genes regulated by these transcription factors.

\section{Acknowledgements}

The present study was supported by Consejo Nacional de Ciencia y Tecnología (CONACyT)-Mexico (grant number 78764-M) for MBL.

\section{References}

1. Ahn AH and Kunkel LM: The structural and functional diversity of dystrophin. Nat Genet 3: 283-291, 1993.

2. Koenig M, Monaco AP and Kunkel LM: The complete sequence of dystrophin predicts a rod-shaped cytoskeletal protein. Cell 53: 219-228, 1988.

3. Bar S, Barnea E, Levy Z, Neuman S, Yaffe D and Nudel U: A novel product of the Duchenne muscular dystrophy gene which greatly differs from the known isoforms in its structure and tissue distribution. Biochem J 272: 557-560, 1990.

4. Byers TJ, Lidov HG and Kunkel LM: An alternative dystrophin transcript specific to peripheral nerve. Nat Genet 4: 77-81, 1993.

5. D'Souza VN, Nguyen TM, Morris GE, Karges W, Pillers DA and Ray PN: A novel dystrophin isoform is required for normal retinal electrophysiology. Hum Mol Genet 4: 837-842, 1995.

6. Lidov HG, Selig S and Kunkel LM: Dp140: A novel 140 kDa CNS transcript from the dystrophin locus. Hum Mol Genet 4: 329-335, 1995.

7. Greenberg DS, Schatz Y, Levy Z, Pizzo P, Yaffe D and Nudel U: Reduced levels of dystrophin associated proteins in the brains of mice deficient for Dp71. Hum Mol Genet 5: 1299-1303, 1996.

8. Hugnot JP, Gilgenkrantz H, Vincent N, Chafey P, Morris GE, Monaco AP, Berwald-Netter Y, Koulakoff A, Kaplan JC, Kahn A, et al: Distal transcript of the dystrophin gene initiated from an alternative first exon and encoding a $75-\mathrm{kDa}$ protein widely distributed in nonmuscle tissues. Proc Natl Acad Sci USA 89: 7506-7510, 1992

9. Greenberg DS, Sunada Y, Campbell KP, Yaffe D and Nudel U: Exogenous Dp71 restores the levels of dystrophin associated proteins but does not alleviate muscle damage in mdx mice. Nat Genet 8: 340-344, 1994.

10. Cox GA, Sunada Y, Campbell KP and Chamberlain JS: Dp71 can restore the dystrophin-associated glycoprotein complex in muscle but fails to prevent dystrophy. Nat Genet 8: 333-339, 1994.

11. Sarig R, Mezger-Lallemand V, Gitelman I, Davis C, Fuchs O, Yaffe D and Nudel U: Targeted inactivation of Dp71, the major non-muscle product of the DMD gene: Differential activity of the Dp71 promoter during development. Hum Mol Genet 8: 1-10, 1999.

12. Lambert M, Chafey P, Hugnot JP, Koulakoff A, Berwald-Netter Y, Billard C, Morris GE, Kahn A, Kaplan JC and Gilgenkrantz H: Expression of the transcripts initiated in the 62nd intron of the dystrophin gene. Neuromuscul Disord 3: 519-524, 1993.

13. Acosta R, Montanez C, Fuentes-Mera L, Gonzalez E, Gómez P, Quintero-Mora L, Mornet D, Alvarez-Salas LM and Cisneros B: Dystrophin Dp71 is required for neurite outgrowth in PC12 cells. Exp Cell Res 296: 265-275, 2004.

14. Enríquez-Aragón JA, Cerna-Cortès J, Bermúdez de León M, García-Sierra F, González E, Mornet D and Cisneros B: Dystrophin Dp71 in PC12 cell adhesion. Neuroreport 16: 235-238, 2005.

15. Tadayoni R, Rendon A, Soria-Jasso LE and Cisneros B: Dystrophin Dp71: the smallest but multifunctional product of the Duchenne muscular dystrophy gene. Mol Neurobiol 45: 43-60, 2012.

16. Villarreal-Silva M, Centeno-Cruz F, Suàrez-Sànchez R, Garrido E and Cisneros B: Knockdown of dystrophin Dp71 impairs PC12 cells cycle: Localization in the spindle and cytokinesis structures implies a role for Dp71 in cell division. PLoS One 6: e23504, 2011. 
17. de León MB, Montañez C, Gómez P, Morales-Lázaro SL, Tapia-Ramírez V, Valadez-Graham V, Recillas-Targa F, Yaffe D, Nudel U and Cisneros B: Dystrophin Dp71 expression is down-regulated during myogenesis: Role of Sp1 and Sp3 on the Dp71 promoter activity. J Biol Chem 280: 5290-5299, 2005.

18. Peñuelas-Urquides K,Becerril-EsquivelC,Mendoza-de-León LC, Silva-Ramírez B, Dávila-Velderrain J, Cisneros B and de León MB: Transcription factors YY1, Sp1 and Sp3 modulate dystrophin Dp71 gene expression in hepatic cells. Biochem J 473: 1967-1976, 2016.

19. Morales-Làzaro SL, Gonzàlez-Ramirez R, Gòmez P, Tapia-Ramirez V, de León MB and Cisneros B: Induction of dystrophin Dp71 expression during neuronal differentiation: Opposite roles of Sp1 and AP2alpha in Dp71 promoter activity. J Neurochem 112: 474-485, 2010.

20. Gerets HH, Tilmant K, Gerin B, Chanteux H, Depelchin BO, Dhalluin $S$ and Atienzar FA: Characterization of primary human hepatocytes, HepG2 cells and HepaRG cells at the mRNA level and CYP activity in response to inducers and their predictivity for the detection of human hepatotoxins. Cell Biol Toxicol 28 : 69-87, 2012.

21. Volkov MS, Bolotina NA, Evteev VA and Koblyakov VA: Ah-receptor-independent stimulation of hepatoma 27 culture cell proliferation by polycyclic aromatic hydrocarbons. Biochemistry 77: 201-207, 2012.

22. Bermúdez de Leòn M, Gómez P, Elizondo G,Zatarain-Palacios R, García-Sierra F and Cisneros B: Beta-naphthoflavone represses dystrophin Dp71 expression in hepatic cells. Biochim Biophys Acta 1759: 152-158, 2006.

23. López-Terrada D, Cheung SW, Finegold MJ and Knowles BB: Hep G2 is a hepatoblastoma-derived cell line. Hum Pathol 40: $1512-1515,2009$
24. Livak KJ and Schmittgen TD: Analysis of relative gene expression data using real-time quantitative PCR and the $2^{-\Delta \Delta C \mathrm{~T}}$ method. Methods 25: 402-408, 2001.

25. Schreiber E, Matthias P, Müller MM and Schaffner W: Rapid detection of octamer binding proteins with 'mini-extracts', prepared from a small number of cells. Nucleic Acids Res 17: $6419,1989$.

26. Tennyson CN, Dally GY, Ray PN and Worton RG: Expression of the dystrophin isoform Dp71 in differentiating human fetal myogenic cultures. Hum Mol Genet 5: 1559-1566, 1996.

27. Jokela TA, Makkonen KM, Oikari S, Kärnä R, Koli E, Hart GW, Tammi RH, Carlberg C and Tammi MI: Cellular content of UDP- $N$-acetylhexosamines controls hyaluronan synthase 2 expression and correlates with $O$-linked $N$-acetylglucosamine modification of transcription factors YY1 and SP1. J Biol Chem 286: 33632-33640, 2011.

28. Tan NY and Khachigian LM: Sp1 phosphorylation and its regulation of gene transcription. Mol Cell Biol 29: 2483-2488, 2009.

29. Chiba T, Chihara J and Furue M: Role of the arylhydrocarbon receptor (AhR) in the pathology of asthma and COPD. J Allergy 2012: 372384, 2012.

30. Nebert DW, Roe AL, Dieter MZ, Solis WA, Yang Y and Dalton TP: Role of the aromatic hydrocarbon receptor and $[A h]$ gene battery in the oxidative stress response, cell cycle control, and apoptosis. Biochem Pharmacol 59: 65-85, 2000. 